\section{Região Central Histórica de Santos e o Território Usado: Síntese de Múltiplas Determinações}

\author{
Central Historical Area of Santos City and the Used \\ Territory: Synthesis of Multiple Determinations
}

\section{RESUMO}

O presente trabalho é produto de um estudo bibliográfico, documental e exploratório sobre a Região Central Histórica da Cidade de Santos, que visa compreender o uso do território pelos diversos sujeitos sociais e as expressões da totalidade em movimento dentro desse recorte em particular.

Palavras-chave: Santos. Território Usado. Totalidade. Movimento.

\section{ABSTRACT}

The present work is a product of a bibliographic, documental and exploratory study about the Central Historical Area of Santos City, which aims to comprehend the use of the territory by the various social subjects and the expressions of the moving totality inside of this particular side view.

Keywords: Santos. Used Territory. Totality. Movement.

\section{INTRODUÇÃO}

Síntese de múltiplas determinações, a Região Central Histórica de Santos, outrora valorizada e habitada por famílias tradicionais, era marcada por palacetes e modo de vida peculiar das elites; a partir da década de 1940, passa por um processo de acentuada degradação, expresso no abandono da região por parte dos grupos mais abastados que partiam em direção à orla da cidade. Desde a metade final do século XX até início do XXI, a região esteve esquecida pelo poder público e por parte da sociedade, tornando-se sinônimo, no imaginário coletivo, de pobreza e periculosidade, devido às suas zonas de prostituição e de consumo de drogas, por suas habitações coletivas (cortiços) e por seu grande contingente de população em situação de rua.
Anita Kurka, Ivelize

Universidade Federal de São Paulo. Departamento de Saúde, Educação e Sociedade, São Paulo, Brasil 
No entanto, no ano 2003, a Prefeitura Municipal de Santos (PMS), por meio da Secretaria de Planejamento (SEPLAN), lançou o Programa Alegra Centro, pela Lei Complementar no 470, que tem por objetivo a "revitalização" da Região Central Histórica de Santos, através da concessão de incentivos fiscais para determinados empreendimentos que se instalarem em qualquer um dos seus cinco bairros (Vila Mathias, Vila Nova, Paquetá, Centro e Valongo) a fim de que a região volte a ser uma área nobre e um símbolo da riqueza de Santos.

O projeto de pesquisa intitulado "Um estudo bibliográfico, documental e exploratório da Região Central Histórica de Santos" constituiu-se em uma aproximação com a temática de transformação do espaço urbano na área central da cidade de Santos, suscitando questões relevantes para futuros estudos sobre o uso do território e a coexistência de diversos agentes sociais, tais como empresas, estabelecimentos públicos e privados e moradias. A seguir, apresenta-se uma síntese das informações e dos dados coletados durante a pesquisa.

\section{DISCUSSÃO}

A partir da compreensão de que "os homens fazem sua própria história, mas não a fazem segundo sua livre vontade; não a fazem sob circunstâncias de sua escolha e sim sob aquelas com que se defrontam diretamente, legadas e transmitidas pelo passado" [9], torna-se evidente a necessidade de um resgate histórico para propor a análise e compreensão dos processos de transformação dos espaços urbanos em geral.

Em concordância com o assinalado por Karl Marx [8], "o concreto é concreto porque é síntese de múltiplas determinações, isto é, unidade do diverso”, considera-se que a "concretude" da Região Central Histórica de Santos, construída por processos decorrentes do uso do território pelos sujeitos, pelas empresas, por estabelecimentos da sociedade civil, entre outros, numa contínua relação entre o par dialético fixos e fluxos [17], é produto, enquanto síntese e resultado, mas é também ponto de partida para entendimento do real e produtora de relações sociais.

No século XIX, Santos já era uma cidade vibrante, que pulsava, revelando toda a efervescência e os múltiplos eventos ocorridos nos lugares de seu território, como evidencia Tavares ao se referir a alguns dos epítetos recebidos por Santos” [19]: "Porto maldito,' 'Centro sindical no 1 do Brasil', 'Barcelona brasileira,' 'Montecarlo do café,' 'Cidade vermelha', 'Moscouzinha,' 'Porto vermelho', 'Cidade heroica,' 'Moscou brasileira', 'Cidade de Prestes', 'República sindicalista'. Partindo dessas alcunhas recebidas pela cidade, símbolos dos olhares e opiniões a respeito dela, versaremos sobre aspectos e processos históricos e sociais gestados em seu interior.

O porto de Santos, hoje o maior da América Latina, com 13 quilômetros de extensão, era alegoria do crescimento econômico nacional já no início do século XX. Visando uma melhora qualitativa da organização dos serviços marítimos, sua construção foi iniciada no ano de 1888 via concessão a uma empresa privada, a Gaffrêe e Guinle [7]. Em razão da construção do cais em local insalubre, resultou o advento de determinadas doenças, tais como a varíola, peste bubônica e a febre amarela que, adentrando pelo porto, agravaram-se devido às práticas inadequadas dos moradores da cidade, como o 
descarte de dejetos nos quintais das casas ou em vias públicas, sendo a causa da morte de mais da metade da população entre os anos 1890 e 1904. Daí, o porto ser conhecido também pelo adjetivo "maldito".

Os bairros da Região Central Histórica de Santos, marcados por profundas desigualdades sócio-espaciais, durante o século XIX e nas primeiras décadas do século $\mathrm{XX}$, caracterizavam-se pela presença de famílias com grande poder aquisitivo, como a elite cafeeira santista, que compôs o núcleo moderno e de maior importância econômica para a cidade. Por sua vez, os trabalhadores residiam em bairros próximos a essa região, como o Macuco, sendo a orla da cidade reservada aos pescadores tradicionais e a suas famílias. Após a abolição da escravatura e chegada da mão-de-obra estrangeira, determinados bairros passaram a ser referências do processo migratório. Como assinala Matos [10] acerca da imigração portuguesa na cidade de Santos e o uso do território por esse grupo social específico:

O sistema implantado optou preferencialmente pela introdução de europeus e em unidades familiares, o que permitiu aos cafeicultores obter um suprimento de trabalho complementar barato, fornecido pela mão-de-obra feminina e infantil, garantindo o abastecimento de braços durante a colheita, enquanto ao colono, através da cooperação da unidade familiar, tornava-se possível um melhor aproveitamento das oportunidades de ganho. [10]

Ainda decorrente do fluxo migratório, um fato curioso é que o atual bairro Valongo passou a ser conhecido como "Bairro Chinês" devido à imigração japonesa, confusão provocada por chineses e japoneses serem orientais e possuírem fenótipos semelhantes [12]. De acordo com Tavares [19],

Do complexo emaranhado de fatores que distinguiam os bairros, os habitantes da época retiveram a distribuição espacial da população santista. Na década de 1930, tal divisão dava margem para que as pessoas retivessem a imagem de uma heterogeneidade entre os bairros de Santos e uma pretensa homogeneidade dentro de cada um. [19]

Essa concepção é resgatada na memória social e impregnou o imaginário santista, pois a relação dos moradores (especialmente os mais antigos) com os bairros é de grande identificação, como se cada bairro da cidade - e cada habitante dele - possuísse características peculiares que o distinguisse dos demais e que mantivesse proximidade e semelhança apenas entre os sujeitos no interior de cada bairro.

A elite santista que, até o início do século XX vivia, predominantemente, no bairro do Valongo, transfere-se para a Vila Nova, pois, com a expansão do comércio cafeeiro e do porto, o primeiro passa a abrigar inúmeros armazéns de estoque de café. Influenciada por esse contexto, há a construção do Mercado Municipal, no ano 1902, na atual Praça Iguatemi Martins. Composto por boxes que vendiam legumes, frutas, verduras, carnes e peixes, este surge pela necessidade de abastecer a população com produtos alimentícios, tendo, ainda, a prerrogativa de situar-se próximo a um canal marítimo. Em 1906, com a construção da rampa dos atracadouros, a Bacia do Mercado passa a integrar o transporte de cargas e pessoas para o antigo Itapema, localizado na cidade do Guarujá [6]. 
Na atual Rua XV de Novembro, no Centro, agora restaurada, sob a iluminação de época e sobre o calçadão, entre cafés e restaurantes, há o imponente prédio transformado em museu, que outrora abrigou a Bolsa Oficial do Café, nos tempos áureos desse produto, pré-crise de 1929. Nessa época, Santos era conhecida como a "Montecarlo do Café", de famílias tradicionais, elites palacianas, imigrantes (espanhóis, portugueses e japoneses, principalmente) e trabalhadores. Desse processo de coexistência e convivência entre diversos sujeitos sociais e espaços públicos e privados nas cidades, Ana Lanna explicita:

O crescimento urbano foi caracterizado pela edificação de belas casas e palacetes, pela negação do sobrado colonial e das formas de vida nele estabelecidas, pela construção de novos espaços e formas de lazer, pelo aparecimento de lojas, cafés, restaurantes, teatros e parques. Mas foi, ao mesmo tempo, caracterizado pelo aparecimento de cortiços, de bairros populares, de trabalhadores ditos "arruaceiros", "incivilizados”, “vagabundos” que com sua presença e movimento também marcaram as novas cidades.[5]

Os chamados "arruaceiros" eram um símbolo de resistência em uma Santos onde a elite temia ante a possibilidade de revoltas com tendências comunistas ("Moscouzinha") e anarquistas ("Barcelona Brasileira"), vendo-se obrigada a atender a determinadas demandas da classe trabalhadora a fim de manter o porto em pleno funcionamento e assegurando a exportação de café. A cidade foi, ainda, espaço de embates entre o Estado Varguista e os trabalhadores. O porto passa, assim, a ser um local onde a vigilância constante era necessária a fim de evitar influências advindas do exterior que pudessem ser prejudiciais ao que projetava o governo.

O processo de expansão capitalista, com seus efeitos múltiplos, expresso em Santos na "expansão comercial e do porto e as facilidades de comunicação com a praia acabaram gerando um novo conceito de 'morar bem': os mais abastados se foram para a porção meridional da ilha” [14].

A consolidação do porto e as consequentes doenças por ele ocasionadas, bem como o movimento e circulação de trabalhadores na região central, a chegada e o estabelecimento de migrantes e a crise econômica (e social) ocorrida entre 1929 e 1932, que ocasionou a decadência do café, são alguns dos motivos pelos quais as famílias ricas deixaram as imediações do porto e partiram em direção à orla da cidade. Assim, a Região Central Histórica de Santos passou por um acentuado processo de degradação, revelador de desigualdades sócio-espaciais e do "caráter de classe na ocupação do solo" [19].

Os trechos abaixo assinalados, extraídos de publicações de jornais da cidade de Santos, revelam alguns aspectos dos bairros Paquetá, Vila Mathias e Centro, respectivamente, que integram a Região Central Histórica de Santos, evidenciando características da degradação política e social sofrida por aquela localidade:

O Paquetá é delimitado pelas ruas São Francisco e Xavier da Silveira, Constituição e João Otávio. Desse quadrilátero que expõe muita miséria, o desenvolvimento parece passar longe. A própria Secretaria de Planejamento estima que todas as habitações ali são "subnormais", classificação dada a moradias sem condições estruturais nem sanitárias de acolher seres humanos. [1]

“Tô aqui na praça. Para onde é que eu vou? Tô sujo, só com essa roupa, mas nunca fui de pedir nada a ninguém. Tomo banho em torneira de obra, passo fome”. Rafix fala, lembra-se da família que ficou 
numa cidadezinha perdida no Nordeste e seus olhos se enchem de lágrimas. Ao seu redor, há muitas outras pessoas na mesma condição de miséria. Na rua, homens e mulheres passam apressados. Uma mistura de medo e desprezo estampados no rosto. [13]

Onde foi parar aquele mundo de gente e de carros? O silêncio tomou conta do Centro: agora ele pertence aos bêbados, às prostitutas, às famílias dos porões. Pertence a essa gente amargurada. [11]

Desde a metade final do século XX até início do XXI, a Região Central Histórica de Santos esteve esquecida pelo poder público e por parte da sociedade. Ficou conhecida, a partir de então, por suas habitações coletivas (cortiços), suas zonas de prostituição e de consumo de drogas, seu grande contingente de população em situação de rua e de trabalhadores informais, tornando-se sinônimo, no imaginário coletivo, de pobreza e periculosidade.

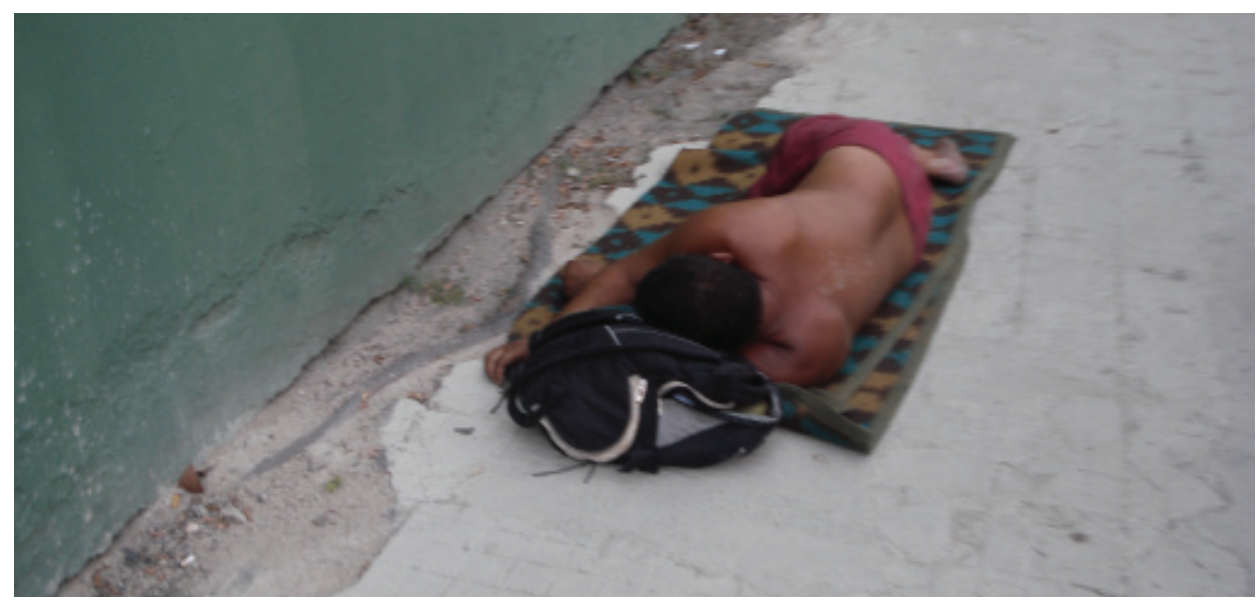

No entanto, no ano 2003, a Prefeitura Municipal de Santos (PMS), por meio da Secretaria de Planejamento (SEPLAN), lançou o Programa Alegra Centro, pela Lei Complementar no 470, que tem por objetivo a "revitalização" da Região Central Histórica de Santos. Trata-se de um projeto higienista, vertical, que não objetiva a emancipação humana e a erradicação da pobreza, mas apenas um manejo das expressões da questão social, no sentido de esconder e camuflar, transferindo-as para outras regiões da cidade, como a Zona Noroeste e a Serra, por exemplo, e da Baixada Santista, a fim de que a região central volte a ser uma área nobre e símbolo da riqueza de Santos, atendendo aos interesses do capital e negligenciando as demandas sociais.

Nas palavras de Comitre,

com o programa Alegra Centro, a região central de Santos vai se reestruturando de acordo com os interesses do poder público, que neste caso muito se aproxima dos ideais privados, por meio da permissão ou não de determinado empreendimento se fixar nesta área. [3]

através da concessão de incentivos fiscais para atividades que estejam direcionadas aos seguintes segmentos: Turismo e Hospedagem, Diversões, Beleza e Higiene Pessoal, Educação e Cultura, Comércio Varejista, Profissionais Liberais e Ateliês Artísticos, Prestadores de Serviços [15].
Figura 1 - Pessoa em situação de rua nas imediações do campus da UNIFESP-BS. 
Ante tais requisitos, o Alegra Centro impulsionou para a região empresas privadas e instituições de ensino, tais como a Universidade Federal de São Paulo (UNIFESP Campus Baixada Santista) e a Faculdade de Tecnologia do Estado de São Paulo (FATEC), atualmente em construção no local da antiga Hospedaria dos Imigrantes, prédio datado de 1912, ambas situadas na Rua Silva Jardim, no bairro Vila Mathias.

Incentivando o turismo, há o projeto Linha Turística - Museu Vivo do Bonde, que percorre um trajeto no Centro e passa pelos pontos de interesse cultural e histórico para a cidade. Junto com tais aparentes indicativos de desenvolvimento e crescimento econômico da região, há a especulação imobiliária, evidenciada na instalação do "Condomínio Trend Home \& Office”, empreendimento de alto padrão, residencial e comercial, localizado entre as ruas Silva Jardim e Emílio Ribas.

Ante essas informações acerca do processo de transformação do espaço urbano e uso do território da Região Central Histórica de Santos, evidenciam-se algumas questões que serão abordadas à luz da concepção teórica de Milton Santos.

Partindo-se do conceito de Milton Santos relativo ao espaço geográfico como produto, mas também como produtor de relações sociais, numa perspectiva dialética, a análise da Região Central Histórica de Santos deve estar pautada na compreensão de que as marcas legadas pelo passado, no movimento histórico de urbanização e ocupação, são fundamentais no esforço de depreender o atual uso do território em questão.

Para Milton Santos, o território só adquire significado quando é usado ou praticado, podendo conceituá-lo como um "conjunto indissociável de sistemas de objetos e sistemas de ações (intencionalidade para a qual é construído)" [4], possuindo sua centralidade no trabalho humano, através da ideação e transformação da natureza pelos homens e mulheres.

A cidade é una e indivisível, sendo seu território usado em duas vertentes: como recurso e como abrigo. Tal conceito pode ser observado materializado na Região Central Histórica de Santos, onde convivem empresas privadas, estabelecimentos da sociedade civil, habitações coletivas (cortiços), residências de famílias tradicionais e moradores em situação de rua, em uma totalidade em movimento.

O território usado como recurso é o espaço de ação do poder hegemônico, com preocupações imediatistas e nenhum ou pouco compromisso com o entorno. É o poder desterritorializado, segundo o qual a lógica de funcionamento pode ser descontínua. Segundo Bauman [2], as corporações têm a liberdade de movimento para mudarem-se quando lhes for conveniente, isto é, quando as possibilidades de lucro estiverem esgotadas, mas as consequências de sua passagem permanecem na localidade, revelando o caráter de uso do território apenas como um recurso volúvel e descartável.

O território como abrigo refere-se ao espaço banal, ao espaço que, enraizado pela ação social, é o suporte da vida de relações, da solidariedade doméstica. É a ação social territorializada, cuja lógica de funcionamento obedece à contiguidade, à vizinhança. Nas cidades, esses territórios convivem, são interdependentes, por vezes apartados, outras vezes sobrepostos; a proximidade e a vizinhança ganham novos contornos de cooperação e conflito, pois o que é vizinho pode não ser próximo, daí originando-se os conflitos que agudizam a vida urbana. Por tal motivo, os conflitos da atualidade não podem ser compreendidos sem uma clara análise dos diferentes usos do território.

Objetivando a aproximação e a apreensão do uso do território pelos diversos agentes 
sociais, foi realizada uma coleta de dados acerca da localização e distribuição nos lugares do território da Região Central Histórica de Santos dos equipamentos públicos de saúde e de assistência social e dos estabelecimentos socioassistenciais filantrópicos, bem como das instituições religiosas.

Por meio de fontes oficiais, como o site da Prefeitura de Santos, foi possível a construção de listagens, que indicaram a presença de 40 equipamentos públicos de saúde, 15 de assistência social, de 16 equipamentos socioassistenciais filantrópicos e 37 instituições religiosas.

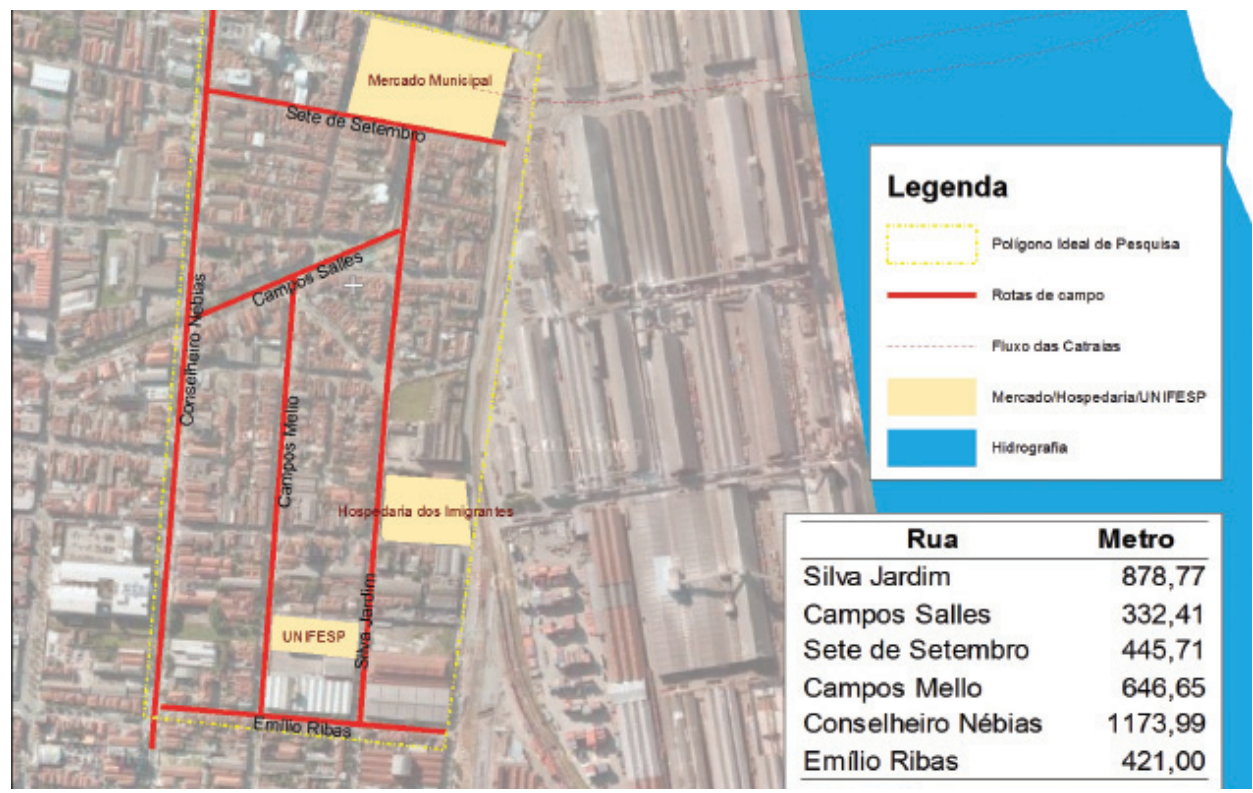

Atendendo o objetivo já mencionado, mas visando uma compreensão para além daquela possibilitada pelos órgãos oficiais, foram selecionadas algumas ruas situadas dentro de um polígono demarcado, que tem como polos a UNIFESP e o Mercado Municipal. Nessa área, foram realizadas visitas de campo, observação e início de uma cartografia da ação, visando um recorte da totalidade em movimento que nos forneça subsídios para o entendimento das relações contraditórias que marcam o uso do território. Por cartografia da ação [16] entende-se o tipo de levantamento espacial que inclui os elementos territoriais e os sujeitos sociais que realmente existem e deles fazem uso.

Tal percurso foi escolhido por abrigar construções antigas e de significado social e histórico, como a Hospedaria dos Imigrantes (1888) e o Mercado Municipal (1902); novos projetos e empreendimentos decorrentes do programa Alegra Centro, como a Universidade Federal de São Paulo (UNIFESP); empresas e galpões industriais relacionados ao Porto de Santos; habitações coletivas (cortiços) e de "famílias tradicionais"; equipamentos socioassistenciais filantrópicos, como o Grupo Amigo do Lar Pobre (GALP); equipamentos públicos, como a Unidade Básica de Saúde (UBS) Martins Fontes; grupo de imigrantes, especialmente portugueses; população em situação de rua; pessoas que trabalham e/ou estudam nas imediações; entre outros sujeitos e equipamentos que coexistem e constroem a vida nos bairros Vila Mathias e Vila Nova. No interior do polígono,
Figura 2 - Área onde foi realizada visita de campo. 
foram localizados 185 estabelecimentos comerciais, 17 estabelecimentos públicos e 23 estabelecimentos da sociedade civil (instituições religiosas e filantrópicas).

As informações obtidas por meio do processo de pesquisa revelam a existência e convivência dos mais variados tipos de imóveis, destinados a fins diversos, cada qual possuindo um público alvo específico, que caracteriza e influencia o cotidiano da vida social, conforme assinalado por Milton Santos:

O dia-a-dia das sociedades gira em torno dos objetos fixos, naturais ou criados, aos quais se aplica o trabalho. Fixos e fluxos combinados caracterizam o modo de vida de cada formação social. Fixos e fluxos influem-se mutuamente. [18]

Embora as cidades não sejam algo planejado e previsível, a distribuição dos fixos nos lugares do território não ocorre de forma aleatória, mas sim atendendo a interesses pré-determinados. Geralmente, os fixos privados atendem a interesses econômicos, de acordo com a lei da oferta e da procura e, os fixos públicos, às demandas sociais, sendo que a localização espacial destes são reflexo dessas necessidades. No entanto, em países de capitalismo tardio, como o Brasil, não há a adoção de "um distributivismo geográfico que sirva de base à desejada justiça social" [18].

Apesar de haver certa defasagem entre os dados da listagem oficial e aqueles coletados através da visita de campo, especialmente ao que se refere a instituições religiosas de pequeno porte, pode-se afirmar que a população residente na Região Central Histórica de Santos não se encontra desassistida, pois há considerável quantidade de equipamentos públicos da saúde e da assistência social nas imediações. Contudo, cabe ressaltar a questão dos problemas estruturais do Sistema Único de Saúde (SUS) e do Sistema Único de Assistência Social (SUAS), em que as necessidades e demandas da população usuária acabam por ultrapassar a possibilidade de ação, devido, entre outros motivos, à escassez de recursos e práticas burocratizadas.

Ainda como elemento revelador de desigualdades sócio-espaciais, pode-se citar o fato de que as instituições religiosas e os estabelecimentos comerciais renomados e de grande porte estão situados em ruas e avenidas de maior visibilidade e facilidade de acesso.

\section{CONCLUSÃO}

Ante o resgate histórico e a análise conceitual apresentados, nota-se que o uso do território por todos os agentes sociais gera um princípio a ser considerado: as desigualdades sócio-espaciais, que constituem a essência da dinâmica dos lugares, devendo ser identificadas e enfrentadas pelos profissionais - da academia e da administração pública - juntamente com a população, na implantação e consolidação de políticas públicas.

As observações feitas e o conhecimento construído acerca da Região Central Histórica de Santos apontam, ainda, para a realização de novas pesquisas, tal como uma que já vem sendo realizada atualmente a respeito das estratégias de sobrevivência de moradores/as de cortiços. 
[1] A TRIBUNA DE SANTOS. Lugar onde os cortiços se impõe. A Tribuna de Santos, Santos, o7 jun. 2010. Disponível em: <http://www.novomilenio.inf.br/ santos/bairronm.htm>. Acesso em: 04 fev. 2013.

[2] BAUMAN, Z. Globalização: as consequências humanas. Tradução: Marcus Penchel. Rio de Janeiro: Jorge Zahar Ed., 1999.

[3] COMITRE, F. A interferência do Estado nas formas de uso e ocupação do solo urbano em áreas centrais. Uma análise do programa Alegra Centro em Santos-SP. In: XII SIMPÓSIO NACIONAL DE GEOGRAFIA URBANA - CIÊNCIA E UTOPIA: POR UMA GEOGRAFIA DO POSSÍVEL, Belo Horizonte, 2011. Anais. Belo Horizonte: UFMG, 2011, v. 1, p. 1-16.

[4] KURKA, A. B. A participação social no território usado: o processo de emancipação do município de Hortolândia. Tese (Doutorado em Serviço Social) - Pontifícia Universidade Católica, São Paulo, 2008.

[5] LANNA, A. L. D. Uma cidade na transição - Santos: 1870-1913. Santos: Editora Hucitec, 1996.

[6] LIMA, A. P. de C. Mercado Municipal de Santos e seu Entorno: preservar para quem? Revista Ceciliana. Santos, Número Especial: Patrimônio Cultural - Memória e Preservação. Maio de 2012.

[7] LÔBO, M. N. Imagens em Circulação: Os Cartões-Postais produzidos na cidade de Santos pelo fotógrafo José Marques Pereira no início do século XX. Dissertação (Mestrado em História) - Instituto de Filosofia e Ciências Humanas da Universidade Estadual de Campinas, Campinas, 2004.

[8] MARX, K. Contribuição à crítica da economia política. São Paulo: Martins Fontes, 1977.

[9] MARX, K. O Dezoito Brumário de Louis Bonaparte. Tradução de Sílvio Donizete Chagas. 4. ed. São Paulo: Centauro, 2006.

[10] MATOS, M. I. S. de. Cotidiano e cultura: história, cidade e trabalho. Bauru: EDUSC, 2002.

[11] MONDIN, L. O Centro, esquecido e abandonado. A Tribuna de Santos, Santos, o3 mar. 1983. Disponível em: <http://www.novomilenio.inf.br/santos/bairronm. htm>. Acesso em: 31 jan. 2013.

[12] MONDIN, L. Prosperidade e decadência, as duas faces do Valongo. A Tribuna de Santos, Santos, 27 jan. 1983. Disponível em: <http://www.novomilenio.inf. $\mathrm{br} /$ santos/bairronm.htm>. Acesso em: 30 jan. 2013.

[13] MONDIN, L. Vila Matias, bairro que tem de tudo um pouco. A Tribuna de Santos, Santos, 24 fev. 1983. Disponível em: <http://www.novomilenio.inf.br/ santos/bairronm.htm>. Acesso em: 10 jan. 2013.

[14] MONDIN, L. Vila Nova e a ironia dos contrastes. A Tribuna de Santos, Santos, 29 jul. 1982. Disponível em: <http://www.novomilenio.inf.br/santos/ho1oob13. htm>. Acesso em: 14 jan. 2013.

[15] PREFEITURA MUNICIPAL DE SANTOS. Lei Complementar no 470, de o5 de fevereiro de 2003. Cria o Programa de Revitalização e Desenvolvimento da 
Região Central Histórica de Santos - Alegra Santos. Diário Oficial [da] Câmara Municipal de Santos, Santos, 30 dez 2002.

[16] RIBEIRO, A. C. T.; SILVA, C. A. da; SCHIPPER, I. Cartografia da ação e a juventude da cidade: trajetórias de método. In: Ribeiro, A. C. T. (Org.) Cartografia da ação e movimentos da sociedade: desafios das experiências urbanas. Rio de Janeiro: Lamparina, 2011.

[17] SANTOS, M. O espaço do cidadão. São Paulo: Nobel, 1987.

[18] SANTOS, M. O país distorcido. São Paulo: Publifolha, 1985.

[19] TAVARES, R. R. A “Moscouzinha” brasileira: cenários e personagens do cotidiano operário de Santos $(1930$ - 1954). São Paulo: Associação Editorial Humanitas: Fapesp, 2007.

ANITA KURKA professora do curso de Serviço Social da Universidade Federal de São Paulo - Campus Baixada Santista (UNIFESP-BS) e responsável pelo grupo de estudos Território Usado e Memória Social, ligado ao Núcleo de Políticas Públicas Sociais

IVelize ferRAZ graduanda em Serviço Social da Universidade Federal de São Paulo - Campus Baixada Santista (UNIFESP-BS) - e-mail: ivelize.ferraz@gmail.com

JULIANA ANASTÁcio graduanda em Serviço Social pela Universidade Federal de São PauloCampus Baixada Santista (UNIFESP-BS) 